Paper No. 151-9

Presentation Time: 4:00 PM

\title{
LANDSLIDE INVENTORY APPROACH FOR REGIONAL-SCALE HAZARD ASSESSMENT IN A DATA-POOR CONTEXT IN TROPICAL AFRICA
}

MONSIEURS, Elise G.M. ${ }^{1}$, MAKI MATESO, Jean-Claude ${ }^{2}$, JACOBS, Liesbet ${ }^{3}$, MICHELLIER, Caroline $^{4}$, KERVYN, Matthieu $^{5}$, DEMOULIN, Alain ${ }^{6}$ and DEWITTE, Olivier ${ }^{4}$, (1)F.R.S.-FNRS Research Fellow, Fonds de la Recherche Scientifique, Egmontstraat 5 , Brussel, 1000, Belgium; Department of Earth Sciences, Royal Museum for Central Africa, Leuvensesteenweg 13, Tervuren, 3080, Belgium; Department of Geography, University of Liège, Place du 20 Août 7, Liège, 4000, Belgium; Hydrological Sciences Laboratory, NASA Goddard Space Flight Center, 8800 Greenbelt Rd, Greenbelt, 20771, Belgium, (2)Department of Geophysics, Centre de Recherche en Sciences Naturelles de Lwiro, Lwiro, Congo (The Democratic Republic of the), (3)Department of Earth Sciences, Royal Museum for Central Africa, Leuvensesteenweg 13, Tervuren, 3080, Belgium; Department of Geography, Vrije Universiteit Brussel, Pleinlaan 2, Elsene, 1050, Belgium, (4)Department of Earth Sciences, Royal Museum for Central Africa, Leuvensesteenweg 13, Tervuren, 3080, Belgium, (5)Department of Geography, Vrije Universiteit Brussel, Pleinlaan 2, Elsene, 1050, Belgium, (6)F.R.S.-FNRS Senior Research Associate, Fonds de la Recherche Scientifique, Egmontstraat 5, Brussel, 1000, Belgium; Department of Geography, University of Liège, Place du 20 Août 7, Liège, 4000,Belgium, elise.monsieurs@africamuseum.be

The main bottle-neck in regional landslide hazard assessment is the availability of detailed data on the timing of landslide occurrences. In tropical African regions in particular, the lack of landslide inventories is in sharp contrast with the regions' high landslide susceptibility. Moreover, the intensity and frequency of landslides in these regions is expected to increase in the future in response to increasing demographic pressure and climate change. We present a regional spatiotemporal landslide inventory in a tropical African environment, comprising 143 dated and localized landslide events in the Kivu section of the East African Rift over a time span of 48 years $(1968-2016)$. Events comprised in this inventory have a minimum spatial accuracy of $25 \mathrm{~km}(72 \%$ has been located with an accuracy $<10 \mathrm{~km}$ ) and a known date of occurrence. Reported landslides are found to be distributed over the year in accordance with the rainfall pattern. Demographic pressure is the second most reported causal factor (after rain) for landslides, which is important to highlight in the context of the African population growth projections. We present field observations of landslide events in order to highlight the diversity of landslide processes, but also to illustrate the research constraints imposed by the context of Central Africa. Biases in the inventory are primarily related to landslide processes, landslide impact and the remote context of the study area. A methodological framework is developed to optimize data collection, and minimize biases and uncertainties. The framework also allows for a critical evaluation of the reliability and usability of the collected data in order to move towards landslide hazard assessments in similar data-poor contexts. The validated results indicate that the proposed methodology can lead to a reliable landslide inventory in data-poor context, valuable for regional landslide hazard assessment.

Session No. 151

T242. Current Trends in Landslide Monitoring: New Techniques, Methods, Successes, Failures, and Case Studies III Monday, 23 October 2017: 1:30 PM-5:30 PM

Skagit 5 (The Conference Center)

Geological Society of America Abstracts with Programs. Vol. 49, No. 6 doi: 10.1130/abs/2017AM-299476

(C) Copyright 2017 The Geological Society of America (GSA), all rights reserved. Permission is hereby granted to the author(s) of this abstract to reproduce and distribute it freely, for noncommercial purposes. Permission is hereby granted to any individual scientist to download a single copy of this electronic file and reproduce up to 20 paper copies for noncommercial purposes advancing science and education, including classroom use, providing all reproductions include the complete content shown here, including the author information. All other forms of reproduction and/or transmittal are prohibited without written permission from GSA Copyright Permissions.

Back to: T242. Current Trends in Landslide Monitoring: New Techniques, Methods, Successes, Failures, and Case Studies III 